\title{
Effect of Replacement of Pyruvate/Lactate in Culture Medium with Glucose on Preimplantation Development of Porcine Embryos In Vitro
}

\author{
Ni Wayan Kurniani KARJA2), Sergey MEDVEDEV ${ }^{1)}$, Akira ONISHI'), \\ Dai-Ichiro FUCHIMOTO ${ }^{1)}$, Masaki IWAMOTO ${ }^{1,3)}$, Takeshige OTOI $^{2)}$ and \\ Takashi NAGAI ${ }^{4)}$
}

${ }^{1)}$ Developmental Biology Department, National Institute of Agrobiological Sciences, Tsukuba, ${ }^{2)}$ Laboratory of Animal Reproduction and Biotechnology, Department of Veterinary Sciences, Yamaguchi University, Yamaguchi, ${ }^{3)}$ Prime Tech Ltd., Ibaraki, ${ }^{4)}$ National Institute of Livestock and Grassland Science, 2 Ikenodai, Tsukuba, Ibaraki 305-0901, Japan

\#Present:Department of Biology, University of Pennsy/vania, Philadelphia, Pennsylvania

19104-6018, USA

\begin{abstract}
The effect of glucose supplementation at different times in in vitro culture on the developmental competence of in vitro produced (IVP) porcine embryos was examined. In Experiment 1 , when IVP embryos were cultured in modified NCSU-37 supplemented with pyruvate and lactate (IVC-pyr/lac) for $0 \mathrm{~h}, 24 \mathrm{~h}, 48 \mathrm{~h}, 72 \mathrm{~h}, 96 \mathrm{~h}$, or $118 \mathrm{~h}$ and subsequently in modified NCSU-37 supplemented with glucose (IVC-glu) until Day 6 (Day 0=day of in vitro fertilization), the rates of blastocyst formation were significantly higher in embryos cultured in IVC-pyr/lac for 24 or $48 \mathrm{~h}$ $(24.4 \%$ and $23.0 \%$, respectively) than in embryos cultured in IVC-pyr/lac for the whole culture period $(14.5 \%)$. However, there were no significant differences between embryos obtained after the energy source replacement and embryos cultured in IVC-glu for the whole culture period on the rates $(15.2 \%-$ $24.4 \%$, and $16.8 \%$ respectively). Replacement of pyruvate/lactate with glucose at $58 \mathrm{~h}$ of culture in Experiment 2 significantly enhanced the rate (31.3\%) compared to those after replacement at $48 \mathrm{~h}, 53 \mathrm{~h}$ and $63 \mathrm{~h}$ of culture $(20.6 \%, 20.8 \%$, and $21.1 \%$, respectively). In conclusion, replacement of pyruvate/ lactate with glucose as the energy substrate was optimal at $58 \mathrm{~h}$ of culture for the development of porcine embryos to the blastocyst stage.
\end{abstract}

Key words: Glucose, Pyruvate, Lactate, Pig embryos, IVC

(J. Reprod. Dev. 50: 587-592, 2004)

$\mathbf{T}$ he role and effect of glucose as a major energy substrate in the composition of an embryo culture on preimplantation embryo development in vitro has been demonstrated in many species. Most reports show that glucose inhibits embryo development before compaction or before the blastocyst stage in mice [1-4] and cattle [5]. In

Accepted for publication: June 4, 2004

Correspondence: T. Nagai (e-mail: taku@affrc.go.jp) contrast, glucose is inhibitory to hamster embryo development in all the preimplantation stages [6, 7]. Also it has been suggested that developmental responses of preimplantation embryos to glucose in vitro depend both on the stage and interactions with other substrates in the medium [8] and seem to be species-specific [9]. A better understanding of the metabolism or the energy substrate and nutrient preferences of preimplantation embryos 
may provide an insight into their metabolic requirements.

Swain et al. [9] reported that the metabolism of porcine embryos produced both in vivo and in vitro is different from that of other species, as they metabolize glucose throughout preimplantation development. Flood and Weibold [10] demonstrated that glucose utilization in porcine embryos produced in vivo increases during early development until compaction and blastulation. In contrast in vitro development of in vitro-derived porcine embryos at the earliest preimplantation stages can be supported by pyruvate and lactate [11-13]. A previous study by us reported that replacement of pyruvate and lactate with glucose, as energy substrate at $48 \mathrm{~h}$ of culture enhanced blastocyst formation and the quality of the in vitro produced (IVP) porcine blastocysts [13]. Furthermore our most recent study showed that the replacement at $58 \mathrm{~h}$ of culture was better than at 46 $h$ for the development of IVP embryos to the blastocyst stage [14]. However, because glycolytic activity of in vitro-derived porcine embryos was reported to increase around the eight-cell stage [10], and although there was a wide variety of developmental embryonic stages at Day 2 (Day $0=$ day of in vitro fertilization) of culture (two-to eightcell stages with most of them at the late four-cell stage) [13], only replacement at 46, 48 and $58 \mathrm{~h}$ after IVC of IVP embryos were compared in those studies. Thus the exact time during the early cleavage stages, when the utilization of glucose as an energy source is optimal, needs to be determined for the effective in vitro production of porcine embryos. The purpose of this study was to examine the effects of glucose supplementation at different times of culture on the developmental competence of IVP porcine embryos.

\section{Materials and Methods}

\section{Oocyte collection and in vitro maturation (IVM)}

Porcine cumulus-oocyte complexes (COCs) were matured and fertilized in vitro according to Kikuchi et al. [13]. Porcine ovaries were obtained from prepubertal gilts at a local slaughterhouse and transported to the laboratory at $35 \mathrm{C}$. COCs were aspirated through an 18-gauge needle into a disposable 10-ml syringe from follicles of 3-6 mm in diameter, and were collected in tissue culture medium (TCM) 199 with Hanks' salt (Sigma Chemical Co., St. Louis, MO, USA) supplemented with $10 \%$ (v:v) fetal calf serum (Cell and Molecular Technology., USA), $20 \mathrm{mM}$ Hepes (Dojindo Laboratories, Japan), $100 \mathrm{IU} / \mathrm{ml}$ penicillin $\mathrm{G}$ potassium and $0.1 \mathrm{mg} / \mathrm{ml}$ streptomycin sulfate. Only COCs with multilayered compact cumulus cells and evenly granulated cytoplasm were selected. Groups of 40-50 COCs were cultured for 20-22 h in $500 \mu \mathrm{l}$ of maturation medium in a fourwell dish (Nunclon Multidishes; Nalge Nunc International, Denmark). The maturation medium consisted of a modified North Carolina State University (NCSU)-37 solution supplemented with $10 \%(\mathrm{v}: \mathrm{v})$ porcine follicular fluid, $0.6 \mathrm{mM}$ cysteine, $1 \mathrm{mM}$ dibutyryl cyclic AMP (dbcAMP; Sigma Chemical Co., St. Louis, MO, USA), $50 \mu \mathrm{M} \beta$ mercaptoethanol (Wako, Japan), 10 IU/ml PMSG (Sankyo, Japan), and $10 \mathrm{IU} / \mathrm{ml}$ human chorionic gonadotropin (Sankyo, Japan). They were subsequently cultured in the NCSU-37 solution without dbcAMP and hormones for $24 \mathrm{~h}$. All cultures were performed at $38.5 \mathrm{C}, 5 \% \mathrm{O}_{2}, 5 \% \mathrm{CO}_{2}$, and $90 \% \mathrm{~N}_{2}$.

\section{In vitro fertilization (IVF) and embryo culture}

Frozen spermatozoa were thawed and preincubated for $15 \mathrm{~min}$ at $38.5 \mathrm{C}$ in TCM-199 with Earle's salts (Gibco Life Technologies Inc., Grand Island, NY, USA) adjusted to $\mathrm{pH}$ 7.8. A portion (10 $\mu \mathrm{l})$ of preincubated spermatozoa was introduced into $90 \mu \mathrm{l}$ of fertilization medium containing 10-15 oocytes. The fertilization medium consisted of 90 $\mathrm{mM} \mathrm{NaCl}, 12 \mathrm{mM} \mathrm{KCl}, 25 \mathrm{mM} \mathrm{NaHCO}, 0.5 \mathrm{mM}$ $\mathrm{NaH}_{2} \mathrm{PO}_{4}, 0,5 \mathrm{mM} \mathrm{MgSO}, 10 \mathrm{mM}$ sodium lactate, $0.5 \%$ bovine serum albumin (BSA; Fraction V; Sigma Chemical Co., St. Louis, MO, USA), and 5 $\mathrm{mM}$ caffeine benzonate (Sigma Chemical Co., St. Louis, MO, USA). The final sperm concentration was $1 \times 10^{5} / \mathrm{ml}$. Five hours after co-incubation with spermatozoa, cumulus cells surrounding zygotes were removed by pipetting with a small-bore pipette and cultured in IVC medium. The basic medium for embryo development was modified NCSU-37 medium (mNCSU-37) containing $4 \mathrm{mg} /$ ml BSA and $50 \mu \mathrm{M} \beta$-mercaptoethanol.

Assessment of the total cell numbers in the blastocyst

The total cell number in the blastocyst at Day 6 (Day $0=$ day of IVF) was determined after nuclear staining in the presence of $20 \mu \mathrm{g} / \mathrm{ml}$ Hoechst 33342 
(Sigma Chemical Co., St. Louis, MO, USA) for 15 $\mathrm{min}$ at $37 \mathrm{C}$. Fluorescent staining of the nuclei was visualized with a fluorescence microscope.

\section{Statistical analysis}

The percentages of embryos cleaved and developed to the blastocyst stage were subjected to arc sin transformation before analysis, and then tested by a post hoc, Fisher's protected least significant difference test (PLSD test). The mean cell number of the blastocysts was analyzed by Student's t-test analysis. Differences at a probability of $\mathrm{P}<0.05$ were considered significant.

\section{Experimental design}

Experiment 1: Experiment 1 (6 trials) was conducted to examine the effect of replacement of pyruvate and lactate with glucose as the energy source at different times of culture on the developmental competence of IVP porcine embryos. After being fertilized (day 0), putative zygotes (1158 in total) were cultured in mNCSU-37 $(500 \mathrm{ml})$ supplemented with $0.17 \mathrm{mM}$ sodium pyruvate and $2.73 \mathrm{mM}$ sodium lactate (IVC-pyr/ lac) in 4-well dishes. Embryos (30-50 in each group) were then transferred into mNCSU-37 supplemented with $5.55 \mathrm{mM}$ D-glucose (IVC-glu) at $24 \mathrm{~h}, 48 \mathrm{~h}, 72 \mathrm{~h}, 96 \mathrm{~h}$, or $118 \mathrm{~h}$ of culture. As control groups, putative zygotes were cultured in IVC-pyr/lac or IVC-glu for the whole culture period (IVC-pyr/lac-only and IVC-glucose-only, respectively).

Experiment 2: Because glycolytic activity in in vitro-derived porcine embryos was reported to increase around the eight-cell stage and some embryos developed to that stage before $72 \mathrm{~h}$ of culture in Experiment 1, Experiment 2 (4 trials) was conducted to examine the effect of replacement of pyruvate and lactate with glucose as the energy source at 48 to $63 \mathrm{~h}$ of culture on the developmental competence of IVP porcine embryos. After being fertilized, putative zygotes (543 in total, and 30-50 zygotes in each group) were cultured in IVC-pyr / lac, and then transferred into IVC-glu at $48 \mathrm{~h}, 53 \mathrm{~h}$, $58 \mathrm{~h}$, or $63 \mathrm{~h}$ of culture.

All the embryos were cultured until Day 6, and the development to the blastocyst stage and number of cells per each blastocyst were then assessed.

\section{Results}

When IVM/IVF embryos were cultured in IVC pyr/lac for $24 \mathrm{~h}$ or $48 \mathrm{~h}$ and subsequently in IVCglu until Day 6, the rate of blastocyst formation (24.4\% and $23.0 \%$, respectively) was significantly higher $(\mathrm{P}<0.05)$ than that of IVC-pyr/lac-only group (14.5\%) (Table 1). However, when IVC pyr/ lac was replaced with IVC-glu, there was no significant difference between the energy source replacement groups and the IVC-glucose-only group in terms of the proportions of cleavage, development to the blastocyst stage and mean cell number per each blastocyst (Table 1).

As shown in Table 2, replacement of pyruvate and lactate with glucose in the culture medium at $58 \mathrm{~h}$ of culture significantly enhanced the rate of blastocyst formation compared with zygotes cultured in the medium where the replacement was done at $48 \mathrm{~h}, 53 \mathrm{~h}$ and $63 \mathrm{~h}$ of culture $(31.3 \%$ vs $20.6 \%, 20.8 \%$, and $21.1 \%$, respectively $(\mathrm{P}<0.05))$. However, no effect on the mean cell number was observed.

\section{Discussion}

The results of the present study demonstrated that in the absence of glucose, the development rate of embryos cultured in the medium with pyruvate/ lactate, as the energy source, for the whole culture period was significantly lower than those for embryos cultured in the presence of pyruvate/ lactate in combination with glucose. Replacement of pyruvate/lactate with glucose as the energy source enhanced the preimplantation development of porcine embryos and a significantly higher rate of blastocyst formation was obtained in the presence of glucose at $24 \mathrm{~h}$ to $48 \mathrm{~h}$ of culture compared to without the replacement. It has been reported that embryo metabolism is biphasic; at the time of embryonic activation, energy metabolism switches from the use of lactate and pyruvate via the Krebs cycle and oxidative phosphorylation to the primary use of glucose via the EmbdenMeyerhof pathway $[15,16]$. With regard to this, it has been shown that the absence of glucose in the later preimplantation stages of bovine embryos caused a decrease in the blastocyst total cell number [15]. Kikuchi et al. [10] and Medvedev et al. [14] demonstrated that pyruvate and lactate are 
Table 1. Effect of replacement of pyruvate/lactate in culture medium with glucose at 24 to $118 \mathrm{~h}$ of culture on preimplantation development of porcine embryos in vitro

\begin{tabular}{|c|c|c|c|c|c|}
\hline \multicolumn{2}{|c|}{ Culture medium } & \multirow{2}{*}{$\begin{array}{l}\text { No. of oocytes } \\
\text { examined }\end{array}$} & \multirow{2}{*}{$\begin{array}{c}\text { No (\%) of } \\
\text { oocytes cleaved }\end{array}$} & \multirow{2}{*}{$\begin{array}{l}\text { No. }(\%) \text { of embryos } \\
\text { develop to blastocysts }\end{array}$} & \multirow{2}{*}{$\begin{array}{l}\text { Mean } \pm \text { SEM of total } \\
\text { cell number in blastocyst }\end{array}$} \\
\hline Pyr/lac (h) & Glucose (h) & & & & \\
\hline $0-144$ & - & 234 & $136(58.1)$ & $34(14.5)^{\mathrm{a}}$ & $34.0 \pm 12.8$ \\
\hline- & $0-144$ & 232 & $145(62.5)$ & $39(16.8)^{a, b}$ & $37.3 \pm 15.9$ \\
\hline $0-24$ & 24-144 & 234 & $150(64.1)$ & $57(24.4)^{\mathrm{b}}$ & $42.1 \pm 17.2$ \\
\hline $0-48$ & $48-144$ & 235 & 140 (59.6) & $54(23.0)^{\mathrm{b}}$ & $35.8 \pm 15.1$ \\
\hline $0-72$ & $72-144$ & 223 & $141(63.2)$ & $48(21.5)^{\mathrm{ab}}$ & $35.7 \pm 10.4$ \\
\hline $0-96$ & 96-144 & 246 & $151(61.4)$ & $46(18.7)^{\mathrm{ab}}$ & $39.6 \pm 18.3$ \\
\hline 0-118 & 118-144 & 145 & $93(64.1)$ & $22(15.2)^{\mathrm{ab}}$ & $39.3 \pm 10.3$ \\
\hline
\end{tabular}

a,bValues with different superscripts within the same column are significantly different $(\mathrm{P}<0.05)$.

Table 2. Effect of replacement of pyruvate/lactate in culture medium with glucose at 48 to $64 \mathrm{~h}$ of culture on preimplantation development of porcine embryos in vitro

\begin{tabular}{lccccc}
\hline $\begin{array}{l}\text { Culture medium } \\
\text { Pyr/lac (h) }\end{array}$ & Glucose (h) & $\begin{array}{c}\text { No. of oocytes } \\
\text { examined }\end{array}$ & $\begin{array}{c}\text { No (\%) of } \\
\text { oocytes cleaved }\end{array}$ & $\begin{array}{c}\text { No. (\%) of embryos } \\
\text { develop to blastocysts }\end{array}$ & $\begin{array}{c}\text { Mean } \pm \text { SEM of total } \\
\text { cell number in blastocyst }\end{array}$ \\
\hline $0-48$ & $48-144$ & 131 & $80(61.1)$ & $27(20.6)^{\mathrm{a}}$ & $38.8 \pm 17.0$ \\
$0-53$ & $53-144$ & 136 & $84(61.2)$ & $28(20.8)^{\mathrm{a}}$ & $40.7 \pm 9.4$ \\
$0-58$ & $58-144$ & 134 & $89(66.4)$ & $42(31.3)^{\mathrm{b}}$ & $40.6 \pm 15.7$ \\
$0-63$ & $63-144$ & 142 & $91(64.1)$ & $30(21.1)^{\mathrm{a}}$ & $42.5 \pm 13.6$ \\
\hline
\end{tabular}

a,b Values with different superscripts within the same column are significantly different $(\mathrm{P}<0.05)$.

important energy supplements in porcine, especially for an early embryonic development in vitro, while blastocyst formation requires much energy due to increased protein synthesis levels [17] and to increased activity of the $\mathrm{Na}^{+} / \mathrm{K}^{+}$-ATPase to create the blastocoel cavity [18].

Since there was a tendency for more embryos to develop to the blastocyst stage in the presence of glucose at $24 \mathrm{~h}$ to $72 \mathrm{~h}$ of culture in the present study, the glycolytic activity in IVP porcine embryos seemed to increase after the eight-cell stage [9]. Also the first two days after IVF were suggested to be the prerequisite stage for embryonic genome activation [19], at which stage a four-cell block was observed in porcine [13]. Thus, it is probable that an adequate energy source would enhance the embryonic potential for genomic activation or for overcoming the developmental block. Exposure to glucose starting from $48 \mathrm{~h}$ to 63 $\mathrm{h}$ of culture in the present study (Experiment 2), showed that replacement of pyruvate/lactate with glucose at $58 \mathrm{~h}$ of culture, permitted a greater number of embryos to develop to the blastocyst stage, suggesting that porcine IVP embryos can effectively utilize glucose as energy starting at around $58 \mathrm{~h}$ of culture. Our results were consistent with those reported by Medvedev et al. [14] in which the developmental potency of IVP porcine embryos and the quality of blastocysts obtained depended on when exposure to glucose began. Exposure to glucose starting at $58 \mathrm{~h}$ of culture facilitated the embryos to develop to full blastocysts, but exposure at an earlier stage resulted in roughly half the rate of full blastocyst formation and a substantial increase in the incidence of malformed and dead embryos [14].

When porcine embryos were cultured in the presence of glucose during the whole culture period in the present study, the developmental competence to the blastocyst stage was similar to those found for embryos cultured in the presence of pyruvate/lactate prior to being cultured in glucose supplemented medium. However, although there were no significant differences between the glucose-only group and the energy source replacement groups in the developmental rate, the rates of embryos cultured in the presence of glucose during the whole culture period tended to be lower 
than those for embryos that were cultured in the presence of pyruvate/lactate in combination with glucose, and a similar phenomenon was observed in embryos cultured with pyruvate/lactate during the whole culture period. Our results suggest that glucose utilization during the preimplantation development in porcine embryos follows the pattern observed by Flood and Wielbold [10]. Levels of utilization were relatively low at the early stages, but increased steadily with development. Porcine embryos have been reported to be able to metabolize glucose throughout preimplantation development, and glucose contributed as an energy source $[9,20]$. At the early stages of development (1-4 cell stages), porcine embryos utilize glucose via the pentose phosphate pathway [10]. During the later stages of development, glucose utilization is mostly via the glycolytic pathway. However, it is known that exposure of embryos to high concentrations of glucose during the early embryonic stages causes developmental retardation in many species [4-6, 17]. Kikuchi et al. [13] and Medvedev et al. [14] suggest that glucose supplementation in early development might cause harmful effects, such as oxidative stress on genome activation or difficulty in overcoming the four-cell block at around Day 2 of IVC in porcine. The toxicity of methylglyoxal, a metabolic by-product of glycolysis has been reported to cause inactivation of the intracellular glutathione peroxidase that is responsible for scavenging free oxygen radicals [21]. Perhaps this enzyme is minimally active in early porcine embryos, with a substantial increase in activation at approximately $58 \mathrm{~h}$ of culture [14].

Replacement of pyruvate and lactate with glucose as the energy substrate in the culture medium was optimal at $58 \mathrm{~h}$ of culture for the development of pig embryos to the blastocyst stage.

\section{References}

1. Leese HJ, Barton AM. Pyruvate and glucose uptake by mouse ova and preimplantation embryos. J Reprod Fertil 1984; 72: 9-13.

2. Gardner DK, Leese HJ. The role of glucose and pyruvate transport in regulating nutrient utilization by preimplantation mouse embryos. Development 1988; 104: 423-429.

3. Chatot CL, Tasca RJ, Ziomek CA. Glutamine uptake and utilization by preimplantation mouse embryos in CZB medium. J Reprod Fertil 1990; 89: 335-346.

4. Chatot CL, Ziomek CA, Bavister BD, Lewis JL, Torres I. An improved culture medium supports development of random-bred 1-cell mouse embryos in vitro. J Reprod Fertil 1989; 86: 679-688.

5. Kim JH, Niwa K, Lim JM, Okuda K. Effects of phosphate, energy substrates, and amino acids on development of in vitro-matured, in vitro-fertilized bovine oocytes in a chemically defined, protein-free culture medium. Biol Reprod 1993; 48: 1320-1325.

6. Schini SA, Bavister BD. Two-cell block to development of cultured hamster embryos is caused by phosphate and glucose. Biol Reprod 1988; 39: 1183-1192.

7. Seshagiri PB, Bavister BD. Glucose inhibits development of hamster 8-cell embryos in vitro. Biol Reprod 1989; 40: 599-606.

8. Barnett DK, Bavister BD. What is the relationship between the metabolism of preimplantation embryos and their developmental competence? Mol
Reprod Dev 1996; 43: 105-133.

9. Swain JE, Bormann CL, Clark SG, Walters EM, Wheeler MB, Krisher RL. Use of energy substrates by various stage preimplantation pig embryos produced in vivo and in vitro. Reproduction 2002; 123: 253-260.

10. Flood MR, Wiebold JL. Glucose metabolism by preimplantation pig embryos. J Reprod Fertil 1988; 84: 7-12.

11. Gandhi AP, Lane M, Gardner DK, Krisher RL. Substrate utilization in porcine embryos cultured in NCSU23 and G1.2/G2.2 sequential culture media. Mol Reprod Dev 2001; 58: 269-275.

12. Abeydeera LR. In vitro fertilization and embryo development in pigs. Reprod Suppl 2001; 58: 159-173.

13. Kikuchi K, Onishi A, Kashiwazaki N, Iwamoto M, Noguchi J, Kaneko H, Akita T, Nagai T. Successful piglet production after transfer of blastocysts produced by a modified in vitro system. Biol Reprod 2002; 66: 1033-1041.

14. Medvedev S, Onishi A, Fuchimoto D, Iwamoto M, Nagai T. Advanced in vitro production of pig blastocysts obtained through determining the time for glucose supplementation. J Reprod Develop 2004; 50: 71-76.

15. Rieger D, Loskutoff NM, Betteridge KJ. Developmentally related changes in the metabolism of glucose and glutamine by cattle embryos produced and co-cultured in vitro. J Reprod Fertil 1992; 95: 585-595. 
16. Khurana NK, Niemann H. Energy metabolism in preimplantation bovine embryos derived in vitro or in vivo. Biol Reprod 2000; 62: 847-856.

17. Thompson JG, Sherman ANM, Allen NW, McGowan LT, Tervit HR. Protein content, synthesis and uptake in pre-elongation stage bovine embryos. Mol Reprod Dev 1998; 50: 139-145.

18. Watson AJ. The cell biology of blastocyst development. Mol Reprod Dev 1992; 33: 492-504.

19. Kopecny V. High-resolution outoradiographic studies of comparative nucleologenesis and genome reactivation during early embryogenesis in pig, man and cattle. Reprod Nutr Dev 1989; 29: 589-600.

20. Petters RM, Johnson BH, Reed ML, Archibong AE. Glucose, glutamine and inorganic phosphate in early development of the pig embryo in vitro. J Reprod Fertil 1990; 89: 269-275.

21. Ankrah NA, Appiah-Opong R. Toxicity of low levels of methylglyoxal: depletion of blood glutathione and adverse effect on glucose tolerance in mice. Toxicol Lett 1999; 109: 61-67. 